be analysed if the study of cultural contact is to be placed on a scientific basis. The aim of this series, to which Dr. Mair will herself contribute, and which it is hoped will include among others articles by Dr. I. Schapera, Dr. A. I. Richards, and Dr. M. S. Fortes, is to make a first tentative effort in this direction.

\title{
Education and Culture Contacts.
}

The fourth Summer Seminar in Education at Yale University is to be held from July 3 oth to September 8th. It will be devoted to a study of the social, religious, and educational problems which arise in areas where different races and cultures come into contact with one another, and Dr. Charles T. Loram, Sterling Professor of Education, who is well known to readers of this Journal, will be Director of the Seminar. He will lecture on 'Education and Culture Contacts in South Africa', and will deal with the cultural changes which are taking place among the South African natives as a result of contact with western civilization and their implications for education.

The members of the Seminar, who will be limited to one hundred, will consist of directors of education, superintendents, supervisors, inspectors of schools, principals, and teachers at training colleges and secondary and elementary schools, government officials, missionaries, social workers, and others interested.

Among the lectures to be given the following may be mentioned. Professor Alfred R. Radcliffe-Brown, Professor of Anthropology at the University of Chicago, will give a series of lectures on 'Comparative Sociology' including an analysis of the cultures of different peoples into such elements as health, family life, government, law, agriculture, industry, religion, and recreation, with emphasis on those elements which chiefly concern the educator.

Mr. Arthur I. Mayhew, Joint Secretary of the British Government's Colonial Education Committee, London, will lecture on 'Education in the British Colonies'. His lectures will include a summary of English influence on the education of India from I 800 to I920; a discussion of education and culture contacts in Ceylon, Malaya, Hong Kong, and Palestine; English educational aims, methods, and results in the British dependencies in tropical Africa and in the western Pacific; a comparison of the educational processes of assimilation and adaptation as carried out in India, the Far East, the West Indies, Africa, and elsewhere; and an analysis of the desirability and possibility of cultural unity in education and methods of preserving distinctive characteristics of widely varying civilizations and cultures.

Dr. Thomas Jesse Jones, Educational Director of the Phelps Stokes Fund, New York, who has conducted educational courses in Africa, Greece, and the Southern States, will present 'The Essentials of Education'-an outline analysis of civilization and its educational implications. 
Dr. Thomas J. Woofter, jr., of the Research Department of Sociology at the University of North Carolina, will deal with the 'Education of the American Negro '.

\section{A New Orthography for Kikuyu.}

In 1933 a Committee of protestant and catholic missionaries convened by the Director of Education with an Education Officer as Chairman recommended the use of seven vowel letters in writing Kikuyu, and the symbols $\supset$ and $\varepsilon$ for the open $o$ and $e$. They also recommended the letter $y$ for the velar $n$.

The Government of Kenya has decided to accept these recommendations, so that the new orthography will use the following vowel letters:

and $y$ for velar $n$.

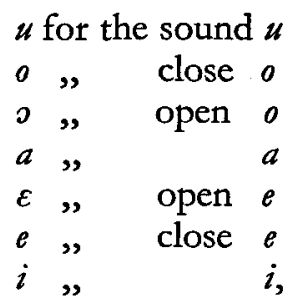

The Government as well as the Committee are to be congratulated on this decision, for it means changing from a very poor system of vowel representation to one which is practical and at the same time phonetically sound. Also the adoption of $y$ is definitely a change for the better, and it is only to be hoped that Swahili will now soon follow suit.

In this connexion the following comment may be made on the consonant system of Kikuyu. The sounds $b, d$, and $g$ are always preceded by a nasal: $m b, n d, n g$; when standing between two vowels, $\nu, \delta$ and $y$ are pronounced instead of $b, d, g$. This shows that $v$ and $b, \delta$ and $d, \gamma$ and $g$ are each one phoneme, the different pronunciation being due to the position of the respective sound. Therefore each of the pairs might be written with one letter, viz. $b$ and $m b, d$ and $n d, g$ and $\eta g$, while the present usage is $v$ and $m b$, th and $n d, g$ and $n g$. The adoption of the principle of phonemes would thus mean a further simplification.

\section{Orthographic Reform in Southern Rhodesia.}

This refers to the changes made in the orthography of Shona which is the general name accepted for the dialects of Mashonaland, hitherto known by the names of individual dialects or, unfortunately, by the name Swina which has crept in no one knows how and is both wrong and unacceptable.

The main dialects of Mashonaland are Karanga, Zezuru, Manyika, Ndau, 